\title{
Human Fetal Mesencephalic Tissue Grafted to Dopamine-Denervated Striatum of Athymic Rats: Light- and Electron-Microscopical Histochemistry and in vivo Chronoamperometric Studies
}

\author{
Ingrid Strömberg, ${ }^{1}$ Per Almqvist, ${ }^{2}$ Marc Bygdeman, ${ }^{3}$ Thomas E. Finger, ${ }^{4}$ Greg Gerhardt, ${ }^{5}$ Ann-Charlotte \\ Granholm, ${ }^{5}$ Thomas J. Mahalik, ${ }^{4}$ Ake Seiger, ${ }^{6}$ Lars Olson, ${ }^{1}$ and Barry Hoffer ${ }^{5}$ \\ 'Department of Histology and Neurobiology, Karolinska Institute, Stockholm, Sweden, Department of Geriatrics, \\ Karolinska Institute, Stockholm, Sweden, 'Department of Obstetrics and Gynecology, Karolinska Hospital, Stockholm, \\ Sweden, ${ }^{4}$ Department of Cellular and Structural Biology, University of Colorado Health Sciences Center, Denver, \\ Colorado, 5 Departments of Pharmacology and Psychiatry, University of Colorado Health Sciences Center, Denver, \\ Colorado, and ${ }^{6}$ Department of Neurological Surgery, University of Miami School of Medicine, Miami, Florida
}

Human fetal mesencephalic tissue obtained from elective first-trimester abortions was grafted to 6-hydroxydopaminedenervated striatum of athymic (nude) rats. After 3-6 months, the transplants were evaluated by light and electron microscopy using antibodies against tryosine hydroxylase (TH), human specific Thy-1 (Thy-1), 5-hydroxytryptamine (5-HT), and laminin. In vivo chronoamperometric studies of $\mathrm{K}^{+}$-induced release of electroactive species were done prior to the histochemical evaluations.

At the light microscopical level, Thy-1-immunoreactivity was evenly distributed throughout the entire transplants. Thy1 -immunoreactive nerve fibers were observed radiating from the graft into the host striatum. In sections that were doublestained with antibodies against Thy-1 and $\mathrm{TH}$, such nerve fibers contained both markers. Also 5-HT-immunoreactive cells were found in the grafts with processes both in the grafts and radiating into host neuropil. Laminin immunohistochemistry showed an even distribution of capillaries in the graft with less density than in host brain, suggesting immaturity of graft tissue.

At the ultrastructural level, TH-immunoreactive axons made symmetric contacts with unlabeled dendritic shafts and dendritic spines within the host brain. A few asymmetric contacts with TH-immunoreactive axons were seen. 5-HT-immunoreactive terminals made both symmetric and asymmetric contacts with unlabeled dendritic shafts and spines.

In vivo chronoamperometry using local application of $\mathbf{K}^{+}$ revealed average signals that were lower on the transplanted side than in control striatum. However, close to the grafts significant amounts of the $K^{\prime}$-evoked signal amplitudes were as large as $1.3 \mu \mathrm{M}$, and the ratio of the reduction to oxidation currents suggested release of a mixture of dopamine and 5-HT.

\footnotetext{
Received Apr. 25, 1988; revised Aug. 1, 1988; accepted Aug. 2, 1988.

This study was supported by the Swedish Medical Research Council (14X03185, 12P-08130, 14X-06555), "Magnus Bergvalls Stiftelse," "Torsten och Ragnar Söderbergs Stiftelser," "Karolinska Institutets Fonder," USPHS Grants NS 09199, AG 04418, AG 06434, and The Miami Project Foundation. We thank Karin Lundströmer, Carina Ohlsson, and Barbro Standwerth for skillful technical assistance and Ida Engqvist for expert secretarial help.

Correspondence should be addressed to Dr. Ingrid Strömberg, Department of Histology and Neurobiology, Karolinska Institute, Box 60400, S-10401 Stockholm, Sweden.

Copyright (C) 1989 Society for Neuroscience $0270-6474 / 89 / 020614-11 \$ 02.00 / 0$
}

Taken together, this study shows that human fetal mesencephalic tissue pieces survive grafting into nude rats, develop normal vascularization, and express coexistence of TH- and Thy-1-immunoreactivity. Human TH- and 5-HT-immunoreactive nerve fibers form synapses in host striatum and release monoamine neurotransmitters.

Intracerebral allografts of fetal dopamine (DA)-containing central neurons can reverse neurotoxin-induced motor asymmetry in rats (Björklund and Stenevi, 1979; Perlow et al., 1979; Björklund et al., 1983; Olson, 1985) and monkeys (Redmond et al., 1986). These toxin-induced deficits, produced by 6 -hydroxydopamine (6-OHDA) and 1-methyl-4-phenyl-1,2,3,6-tetrahydropyridine (MPTP), have been used as experimental models for Parkinson's disease and raised the possibility of using human fetal DA neuroblasts as a therapeutic approach to Parkinson's disease in patients unsuitable for standard pharmacotherapy.

A key prerequisite for such an approach would be to establish that human fetal DA neuroblasts are suitable as donor material. Recent evidence suggests that such human fetal cells can survive grafting to immunocompromised rodent hosts and provide them with a new DA innervation (Brundin et al., 1986; Strömberg et al., 1986). These initial studics have left scveral questions unanswered: Are synapses established? Are appropriate neurotransmitters released after suitable stimulation? We have attempted to provide some answers to these questions by examining the properties of intracerebral xenografts of human mesencephalic neurons placed into athymic "nude" rats. These recipients are devoid of cellular and humoral immune mechanisms (Festing et al., 1978; Vos et al., 1980) and have been shown to be excellent hosts for xenografts of central (Bickford-Wimer et al., 1987; Hall et al., 1987) and peripheral tissues (Hall et al., 1987).

\section{Materials and Methods}

Recipients

Adult athymic nude rats (Harlan Sprague-Dawley, Inc., Indianapolis, IN) were used as recipients in all experiments. They were kept in cages with filter tops, with free access to autoclaved food and boiled water. The rats were unilaterally injected with 6-OHDA ( $8 \mu \mathrm{g} / 4 \mu \mathrm{l}$ saline over $4 \mathrm{~min}$ ) into the nigrostriatal pathway. The coordinates were $4.4 \mathrm{~mm}$ posterior and $1.2 \mathrm{~mm}$ lateral to bregma, and $7.8 \mathrm{~mm}$ below the dura. Apomorphine-induced $(0.05 \mathrm{mg} / \mathrm{kg}$, s.c.) rotations were performed to 
select rats with an expected extensive DA-denervation of striatum (Ungerstedt and Arbuthnott, 1970; Herrera-Marschitz and Ungerstedt, 1984).

\section{Dissection procedure}

Fetal material was obtained after termination of first-trimester pregnancies. Healthy women with an apparently normal pregnancy in the 7th-12th week of gestation, admitted to the hospital for elective abortion, were informed orally and in writing about the aim of the study and the procedure to be used, and they gave their consent. Anonymity was strictly maintained. The abortion was performed by standard lowpressure vacuum aspiration. The fetal tissue fragments were kept in isotonic saline until further processed. The study was approved by the Regional Ethical Committee of the Karolinska Hospital, and all experiments conformed to guidelines of the Swedish Medical Association and the U.S. Public Health Service. The tissue fragments were examined under a stereomicroscope. When the mesencephalic flexure was found, the substantia nigra area was dissected as unilateral pieces including the entire thickness of the brain stem.

\section{Grafting procedure}

Small solid tissue pieces $\left(1-3 \mathrm{~mm}^{3}\right)$ were stereotaxically implanted into striatum. Five rats received 2 implantations (=one nigra) each, with the coordinates $1 \mathrm{~mm}$ anterior, $2.8 \mathrm{~mm}$ lateral to bregma, and $5 \mathrm{~mm}$ below the dura and $0.5 \mathrm{~mm}$ posterior, $3.0 \mathrm{~mm}$ lateral to bregma, and $5.5 \mathrm{~mm}$ below the dura, respectively. Two rats received one graft (= one nigra) each, and the implantation site in these cases was $0.5 \mathrm{~mm}$ anterior and $3.0 \mathrm{~mm}$ lateral to bregma and $5.0 \mathrm{~mm}$ below the dura. The time between abortion and grafting did not exceed $4 \mathrm{hr}$.

\section{Light and electron microscopic cytochemistry}

Four animals were examined using indirect immunofluorescence. The other 3 were examined using light and electron microscopic peroxidaseantiperoxidase techniques, after in vivo electrochemical studies. Both methodologies are detailed below.

Indirect immunofluorescence. Rats were first perfused with $\mathrm{Ca}^{2+}$ - and $\mathrm{Mg}^{2+}$-free Tyrode and then with $4 \%$ paraformaldehyde containing $0.1 \%$ glutaraldehyde in $0.1 \mathrm{M}$ phosphate buffer 3-6 months postgrafting. Thin $(14 \mu \mathrm{m})$ sections were processed for light microscopy using the indirect immunofluorescence technique of Coons (1958). Antibodies used were raised against tyrosine hydroxylase (TH) diluted 1:100, human-specific Thy-1 diluted 1:100, 5-hydroxytryptamine (5-HT) diluted 1:500, and laminin (lam) diluted 1:500, all in phosphate-buffered saline (PBS) with $0.3 \%$ Iriton. The slides were incubated with antibodies overnight at $+4^{\circ} \mathrm{C}$ in a humid atmosphere. They were then rinsed in PBS $3 \times 10$ min before incubation in the second antibody. Fluorescein isothiocyanate (FITC)-conjugated antibodies were used as secondary antibodies, and sections were incubated at room temperature for $1 \mathrm{hr}$ before rinsing and mounting in a mixture of glycerol and PBS (9:1), containing $0.1 \%$ p-phenylene diamine as an antifading agent (Johnson and de C. Nogueira Araujo, 1981). In some cases double staining was performed with antibodies against $\mathrm{TH}$ and Thy- 1 in the same dilutions as above. These incubations were performed in sequence using FITC and rhodamine-conjugated second antibodies.

Peroxidase-antiperoxidase. Anesthetized rats were intracardially injected with $1 \mathrm{ml}$ of $1.0 \%$ sodium nitrite followed by 200 units of sodium heparin, and were then perfused with $4 \%$ paraformaldehyde and $0.2 \%$ glutaraldehyde in $0.1 \mathrm{~m}$ phosphate buffer ( $\mathrm{pH} 7.4$ ). Brains were removed, blocked and postfixed in the same fixative for $3-4 \mathrm{hr}$ at $4^{\circ} \mathrm{C}$ and were then stored overnight in PBS (pH 7.4). Tissue blocks were cryoprotected in increasing concentrations of glycerol and sucrose in phosphate buffer (Eldred et al., 1983).

Tissue was frozen in powdered dry-ice, thawed, and refrozen onto the chuck of a sliding microtome. Serial $60 \mu \mathrm{m}$ sections were taken through the striatum; out of every 3 serial sections, one was used to reconstruct electrode tracts. Remaining sections were stored in PBS at $4^{\circ} \mathrm{C}$ until use in immunocytochemical experiments.

For electron microscopic immunocytochemistry, sections were incubated in $1 \%$ sodium borohydride in phosphate buffer for 30 min. After two 15-min washes in PBS, sections were incubated in PBS containing $5 \%$ milk powder to quench nonspecific binding sites. Sections containing transplants were then incubated in either rabbit anti-1H (diluted 1:500), rabbit anti-5-HT (1:500), or normal rabbit serum (1:
500 ) in PBS containing 5\% milk powder for $24-48 \mathrm{hr}$ at $4^{\circ} \mathrm{C}$. Primary antibodies were localized by the immunoperoxidase method of Sternberger (1979) using 3,3'-diaminobenzidine (DAB) as the chromagen. After the DAB reaction, sections were postfixed in $2 \% \mathrm{OsO}_{4}$ for $45 \mathrm{~min}$; tissue was then dehydrated and flat-embedded in Epon. Immunochemically labeled flat-embedded sections were examined for the presence of clectrode tracts, and blocks near the tracks were cut out and sectioned on a Sorvall ultramicrotome. Ultrathin sections $(70-90 \mathrm{~nm})$ were collected on copper grids and stained with lead citrate. Serial sections, 10 $\mu \mathrm{m}$ through the substantia nigra of each host animal were cut on a cryostat and were prepared for TH immunocytochemistry.

Antibodies. The production and characterization of human-specific Thy-1 antibodies has been described previously (Berglund et al., 1987). TH antibodies were a generous gift from Dr. Norman Weiner, University of Colorado. Antibodies against 5-HT were either a generous gift from Dr. Albert Verhofstad, University of Nijmegen, or purchased from Immunonuclear. Laminin antibody was purchased from Bethesda Research Laboratories, Maryland. Antibody-based detection methods do not permit absolute chemical identification of antigens, and the data should be interpreted accordingly.

\section{In vivo electrochemistry}

Micropipettes containing $120 \mathrm{~mm} \mathrm{~K}{ }^{+}$and $2.5 \mathrm{mM} \mathrm{Ca}^{2+}$ were attached to electrochemical recording electrodes. The potassium solution was locally applied by pressure ejection (Palmer et al., 1980). Electrochemical measurements (Rose et al., 1985; Gerhardt et al., 1986, 1987) were made using Nafion-coated graphite epoxy capillary (GEC) electrodes that are highly selective for monoamine neurotransmitters (Gerhardt et al., 1984, 1987; Nagy et al., 1985). Preparation, characterizalion and calibration of the electrochemical recording electrodes have been described (Gerhardt et al., 1984, 1985, 1986, 1987). An IVEC-5 electrochemical instrument (Medical Systems Corp.) was used to obtain highspeed chronoamperometric measurements $(5 \mathrm{~Hz},-0.2$ to $+0.45 \mathrm{~V}$ square-wave pulses, both oxidation and reduction signals). Signals were digitally integrated during the final $40-100 \mathrm{msec}$ of the oxidation and reduction phases. The ratios of reduction to oxidation currents, observed at the peaks of the oxidation signals, were used as an index of the major species giving rise to the electrochemical signals (Gerhardt et al., 1988a, b).

Electrochemical experiments were initiated in urethane-anesthetized hosts with the insertion of an electrode assembly into a control or transplant reinnervated caudate nucleus. Measurements were repeated every $0.2 \mathrm{sec}$. Once a steady-state baseline response was established at a given recording site, the effects of locally applied $\mathrm{K}^{+}$were investigated. Signal magnitudes, expressed as micromolar change from baseline as well as the rise and half-decay times, were used as indices to quantitate the electrochemical signals (Gerhardt et al., 1986). Variability was expressed as SEM. Statistical comparisons were made using a 2-tailed Student's $t$ test.

\section{Results}

\section{Light microscopy}

Human tissue grafts were located in the center of striatum, and extended 2.5-3.0 $\mathrm{mm}$ below the dorsal border of this structure. At the time of sacrifice, 3-6 months after grafting, the human tissue appeared more translucent than the surrounding, normal striatum and was free of the myelinated nerve fascicles that are characteristic of the striatum. In osmium-treated material osmiophilic blebs, probably representing degenerative debris, were present in fiber fascicles immediately adjacent to the transplant. These features made it easy to distinguish host from graft tissue at the light microscopic level. All rats had surviving transplants. Almost all grafts had increased their volume. Thus, in the cases of 2 implantation sites, the anterior and posterior grafts had often fused.

In counts of $\mathrm{TH}$-immunoreactive cell bodies in the nigral areas, a $95 \%$ reduction in cells was found compared with the control sides. Areas of host striatum remote from the transplants contained few TH-immunoreactive processes. 

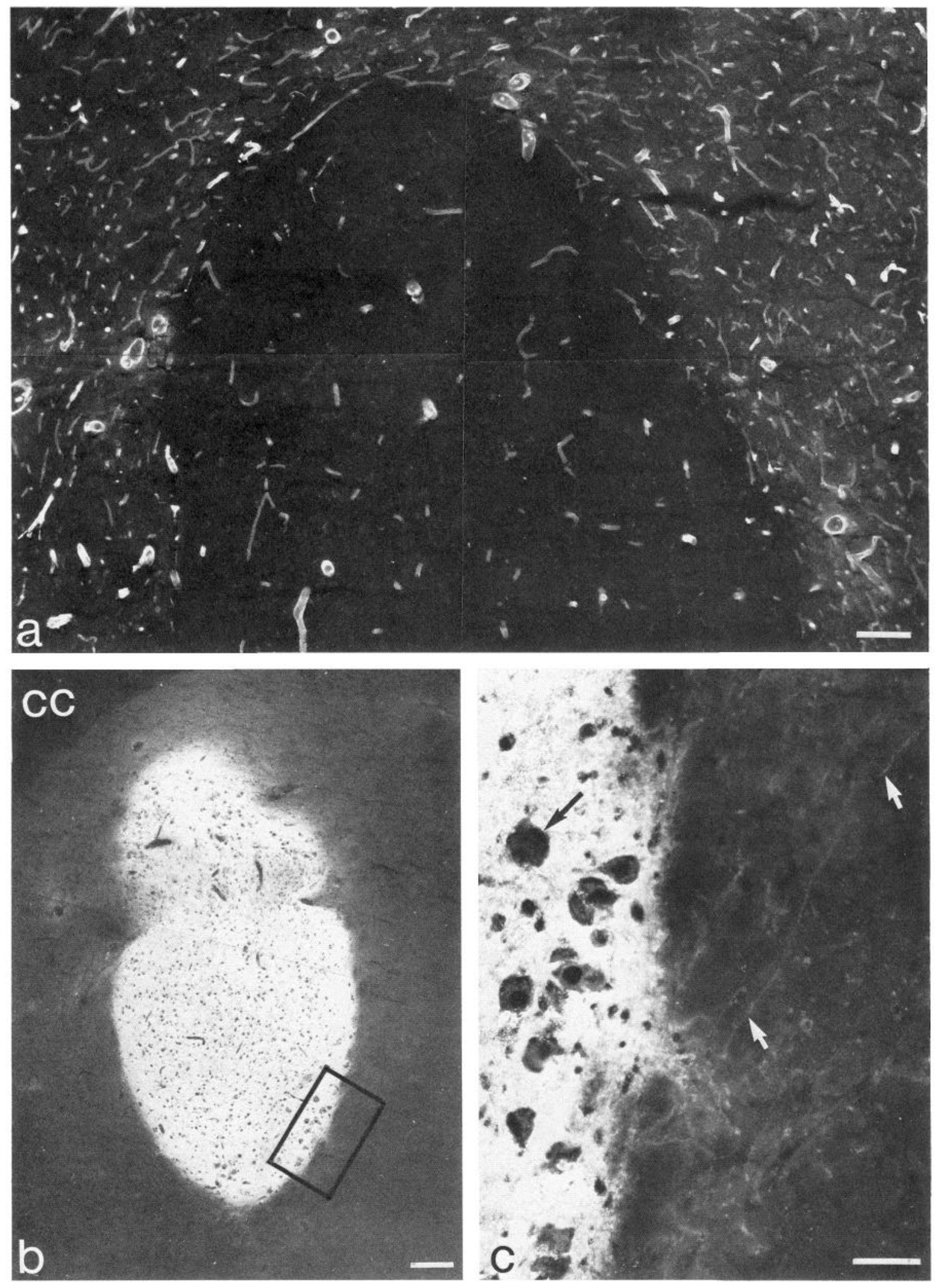

Figure 1. a, Laminin immunoreactivity showing the vascularization of a human nigral graft from a 7 -week-old fetus 4.5 months postgrafting. The capillary network in the graft (darker area in the middle) is less dense than in the host striatum, but the diameter of the capillaries is normal. $b$, Overview from the same transplant as in $a$ processed with Thy-1 antibodies. A part of corpus callosum (CC) is seen in the upper left. Note sharp delineation between Thy-1-positive (=human) and Thy-1-negative (=rat) neuropil. $c$, High magnification of the boxed area in $b$. Large neurons (such as the one labeled by an arrow) in the graft have a negative cytoplasm. Weakly stained Thy-1-immunoreactive nerves are growing into rat host striatum (arrows). Scale bars: $a, 100 \mu \mathrm{m} ; b, 200 \mu \mathrm{m} ; c, 50 \mu \mathrm{m}$. 


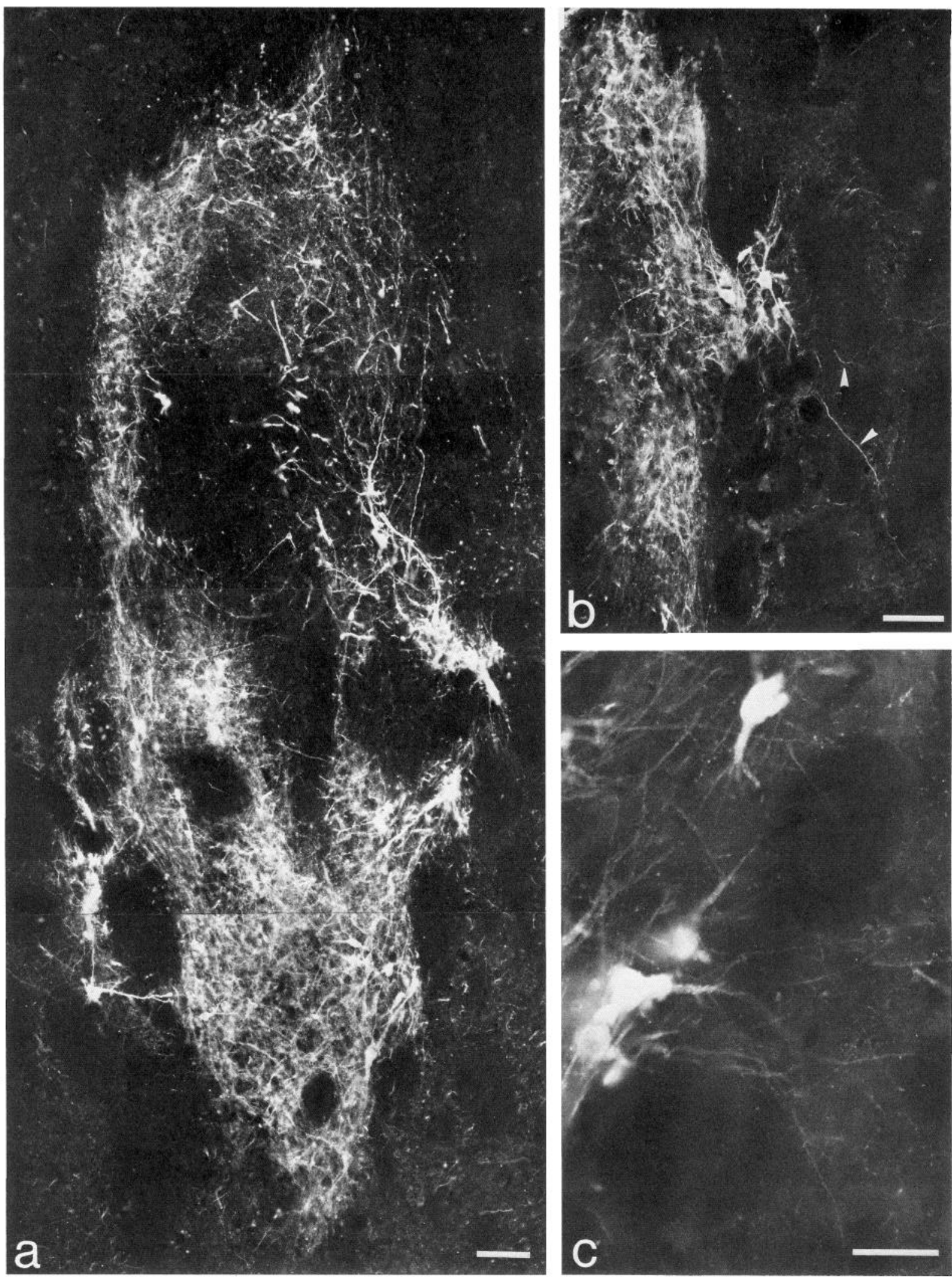

Figure 2. Human fetal nigral grafts in striatum of nude rats. $a$, TH immunoreactivity in an overview of a transplant from a 12-week-old human fetus 3 months postgrafting. $b$, Detail of the same transplant as in $a$. TH-positive nerves (arrowheads) coming from the graft are growing into the host rat striatum. $c$, Transplant from a 10-week-old fetus 5 months postgrafting, showing 5-HT-immunoreactive cells and nerve terminals within the transplant (left). 5-HT-positive neurites are growing into the host striatum (right). Scale bars: $a$ and $b, 100 \mu \mathrm{m} ; c, 50 \mu \mathrm{m}$. 

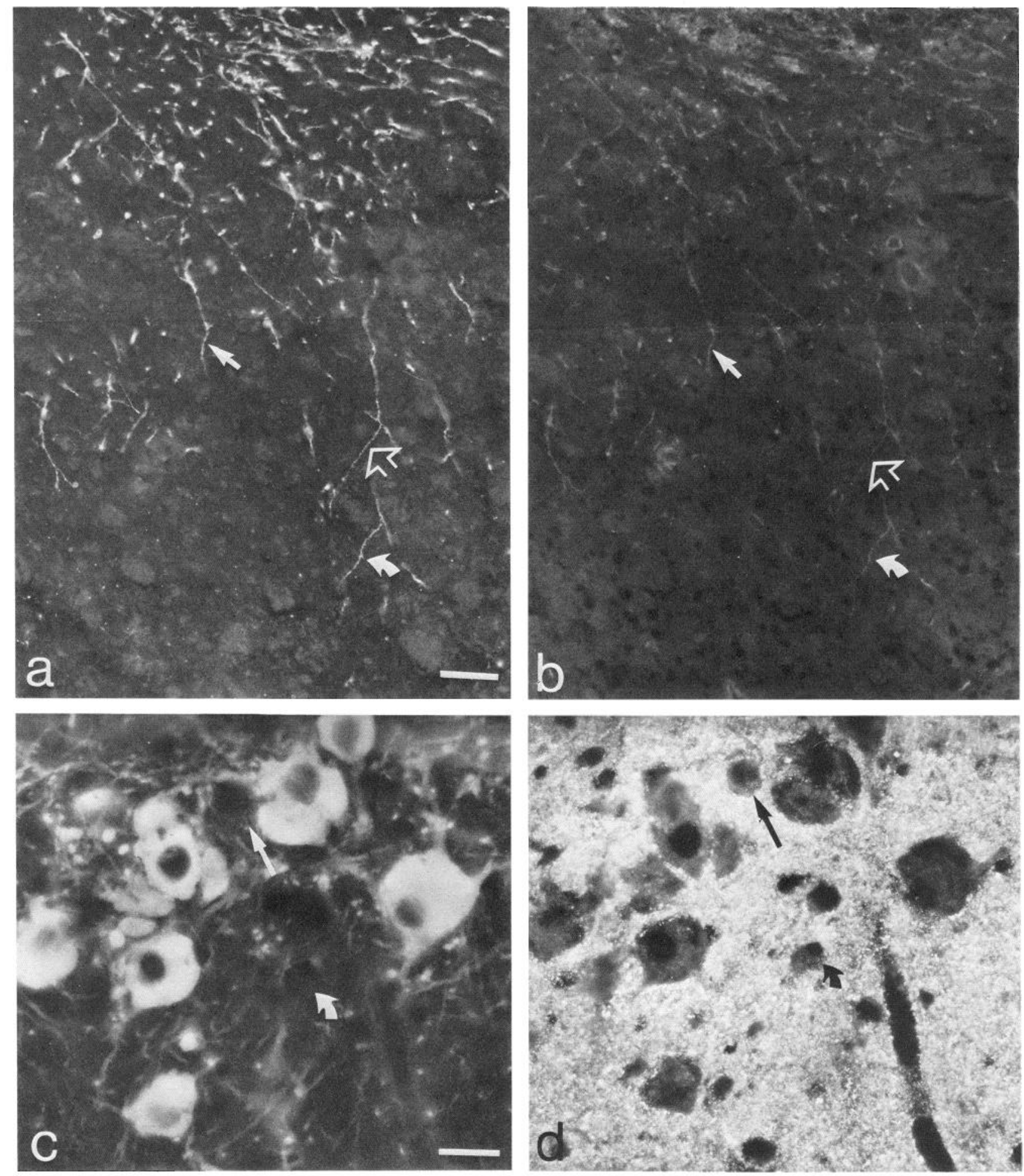

Figure 3. A human nigral graft from a 7-week-old fetus 3 months postgrafting double-stained with antibodies against TH ( $a$ and $c$ ) and human specific Thy-1 $(b$ and $d)$. $a$, TH-positive nerve fibers are seen in host striatum. $b$, Thy-1-immunoreactivity in the same section as in $a$. Arrow pairs show coexistence of TH and Thy- 1 in nerve terminals. $c$, TH-immunoreactive cell bodies in the transplant from the same animal as in $a$ and $b$. $d$ shows Thy-1-immunoreactivity in the same section as in $c$. The TH-immunoreactive cell bodies in $c$ have a Thy-1-negative cytoplasm $(d)$. Two examples of small cells that are both TH and Thy-1 negative are labeled by arrow pairs. Scale bars: $a$ and $b, 50 \mu \mathrm{m} ; c$ and $d, 25 \mu \mathrm{m}$.

In sections processed with a laminin-antibody, a seemingly normal capillary network was shown in the grafts (Fig. 1a). Thinwalled capillaries with a diameter similar to, or slightly larger than, that of capillaries in surrounding host neuropil (as measured in microphotographs of laminin-antibody processed ma- terial) were found. The capillary density was lower than in the surrounding striatal neuropil of the mature rat host brain.

The human-specific Thy-1 antibody gave a positive reaction with all grafts. In contrast to the $\mathrm{TH}$ immunoreactivity (see below), the Thy-1-immunoreactivity was found relatively evenly 

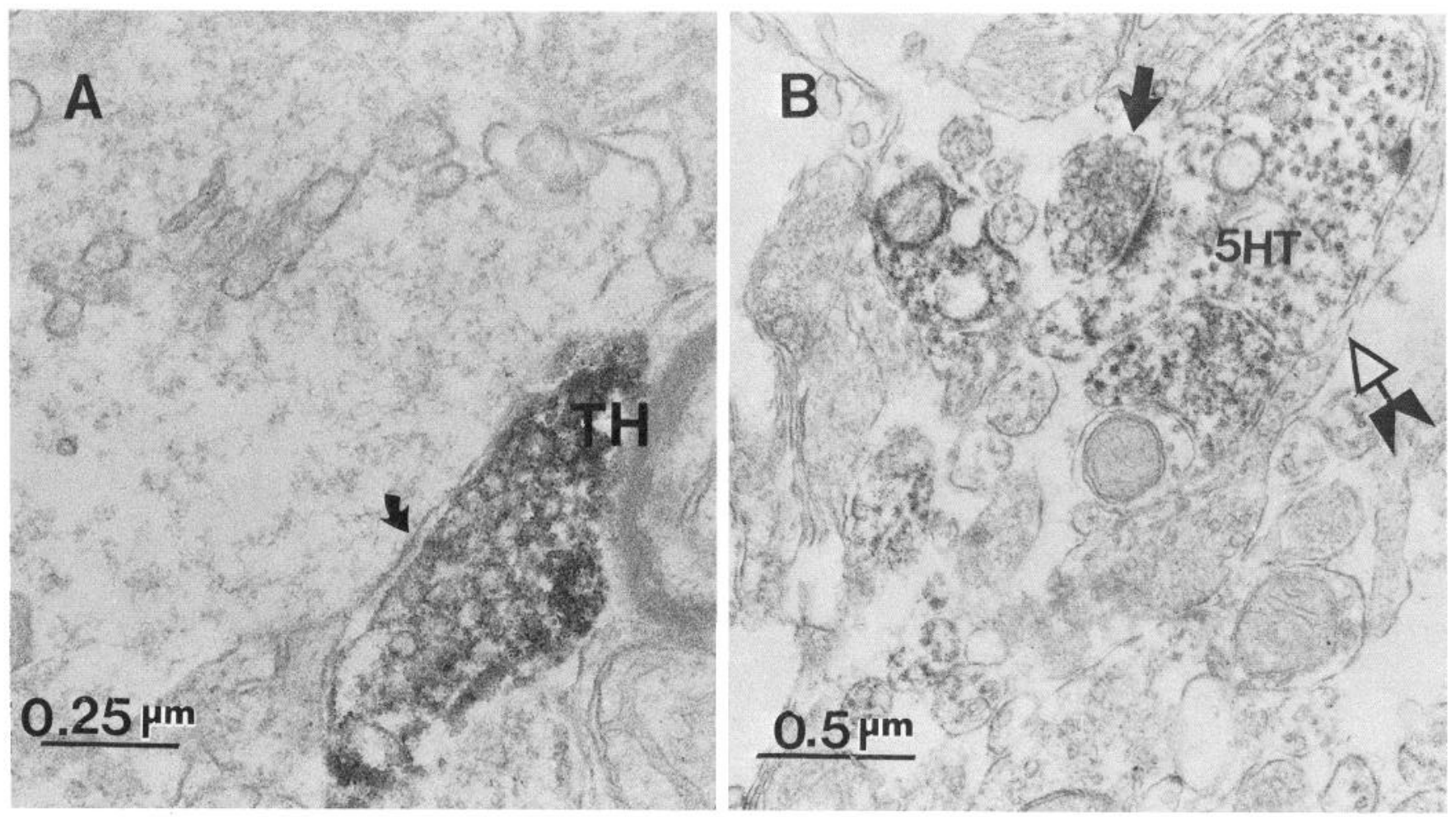

Figure 4. A, PAP immunocytochemistry of a nude rat that received a human nigral transplant from a 9-week-old fetus. A TH-immunoreactive terminal $(T H)$ that forms a symmetric synapse with an unlabeled dendrite as seen 4 months postgrafting. Note slight thickening of postsynaptic membrane (arrow). B, 5-HT-immunoreactivity in a rat that has had a human transplant from a 7-week-old fetus for 6 months. A small 5-HTimmunoreactive terminal (small arrow) forms an asymmetric contact with a 5-HT-like immunoreactive dendrite (large arrow); such contacts are normally not found in striatum of the rat.

distributed throughout the entire graft neuropil (Fig. 1, b,c). In large neurons, however, the perikaryon appeared nonreactive for this marker (Fig. 1c) of a neuronal surface antigen. The large cell bodies were found in the same area as the TH-positive cell bodies. Thy-1-positive neurites from the grafts extended into adjacent portions of Thy-1 negative host striatal neuropil (Fig. $1 c)$.

TH-positive cell bodies and nerve terminals were found in 6 out of 7 animals (Figs. 2, $a, b ; 3, a, c ; 6 c$ ). The TH-immunoreactive cell bodies were generally located in clusters near the edge of the grafts, adjacent to host striatum, while the core of the graft contained fewer TH cell bodies and terminals (Fig. 2a). The TH-positive cell bodies were oval or rounded, with diameters up to approximately $40 \mu \mathrm{m}$. TH-immunoreactive neurons possessed one or more large primary dendrites from which several secondary dendrites branched. The largest neurons were found in a graft derived from the most immature fetus ( 7 week abortion) that had been growing in a rat brain for 4.5 months (Fig. 3c). In transplants coming from a 12 week donor, the cell bodies did not appear as mature 3.5 months postgrafting as those from the 7 week fetus, but they were larger than cell bodies in another graft from the same 12 week fetus that had been growing intracranially for 3 months. In no case could neuromelanin be found in the TH-positive nerve cells.

In all grafts with $\mathrm{TH}$-positive cell bodies, TH-positive nerve fibers were also seen within the transplants (Fig. 2, $a, b$ ). Thick $\mathrm{TH}$-immunoreactive fibers were observed coursing through the neuropil of the graft. The one graft lacking TH-immunoreactive cell bodies served as a useful control in this regard since both it and the surrounding striatum were virtually devoid of $\mathrm{TH}$ - positive processes. In cases with $\mathrm{TH}$-immunoreactive cells in the grafts, immunoreactive processes crossed the graft/host interface (Fig. $2 b$ ), entering the dopamine-denervated host striatum. These fibers often appeared thicker than normal rat striatal DA-containing nerves. In the control striatum TH immunoreactivity was present in fine varicose processes; larger processes were not observed. In contrast, TH-immunoreactive fibers on the grafted side were larger and were readily observed coursing through striatum. In the cases used for electrochemical recording, TH-positive processes were also present in the vicinity of the electrochemical recording sites. In one case, a few scattered TH-positive fibers were present in the cerebral cortex adjacent to the grafted striatum.

Double staining for Thy- 1 and TH revealed that many of the large nerve cell bodies with a Thy-1-negative cytoplasm were TH-positive. Some neurons with a Thy-1-negative cytoplasm were, however, TH-negative (Fig. 3, $c, d$ ). Double staining of TH-immunoreactive nerve fibers seen radiating from the grafts into host neuropil revealed that they were also Thy-1-immunoreactive, strongly suggesting their human origin (Fig. 3, $a, b$ ).

The electrochemical data obtained from 3 animals (see below) suggested that serotonergic fibers from the grafts also innervated the host striatum on the side of the 6-OHDA lesion. Thus, striatal tissue sections through the grafts were also incubated in a rabbit antiserum against 5-HT. In 3 out of 3 rats examined for 5-HT, numerous 5-HT-immunoreactive cell bodies were present in the periphery of the grafts. Many 5-HT-immunoreactive terminals were present within the graft; many varicose 5-HT-immunoreactive processes were also present in the neuropil of the host brain (Fig. $2 c$ ). 


\section{Electron microscopy}

At the ultrastructural level, TH-immunoreactive processes were obscrved in the host caudate neuropil immediately adjacent to the grafted tissue. Many of these processes contained round or slightly oval vesicles and therefore were identified as axons. Vesicle-filled axons made close symmetric-type contacts with dendritic shafts (Fig. 4A) and with dendritic spines; these contacts were characterized by the widening of the synaptic cleft at the point of contact and by the absence of pre- or postsynaptic densities (Fig. 4A). Spines that received symmetric contacts from TH-immunoreactive terminals commonly received an asymmetric contact from an unlabeled axon terminal. The formation of asymmetrical synapses by TH-positive terminals was also observed.

Numerous 5-HT-immunoreactive terminals were present within the neuropil of the host. These terminals made both symmetric and asymmetric synapses with dendritic shafts and dendritic spines. 5-HT-immunoreactive dendrites also were present in the host neuropil; Figure $4 B$ illustrates a 5-HT-immunoreactive terminal forming a synapse with a 5-HT-immunoreactive dendrite. Such contacts were not seen in striatum on the nongrafted, nondenervated side.

\section{Electrochemistry}

Local application of $\mathrm{K}^{+}$into the control side caudate nucleus produced a reproducible and reversible increase of extracellular levels of electroactive species. Such $\mathrm{K}^{+}$-evoked signals had a mean peak amplitude of $2.0 \pm 0.1 \mu \mathrm{M}(n=23$ sites). A representative $\mathrm{K}^{+}$-evoked release is illustrated in Figure $5 A$. The "Ox." curve represents the oxidation of electroactive species released by the $\mathrm{K}^{+}$bolus; the lower tracing ("Red.") represents the current measured for the subsequent reduction of a portion of the oxidation products. Note that the ratio of the 2 currents in this control tissue is about $0.6-0.7$.

Local application of $\mathrm{K}^{+}$in the transplant-reinnervated caudate nucleus yielded average signals that were significantly reduced from control $(p<0.001)$. The average signal amplitudes were $0.5 \pm 0.1 \mu \mathrm{M}(n=22$ sites). However, histologically confirmed electrode placements adjacent to the human fetal substantia nigra grafts yielded $\mathrm{K}^{+}$-evoked signal amplitudes as large as $0.9-$ $1.3 \mu \mathrm{M}$. One such release can be seen in Figure $5 B$. Figure 6 illustrates recording sites from both control (left) and transplantreinnervated (right) sides of a nude rat. The histograms above the coronal slice of rat brain represent the individual release magnitudes recorded from each depth. Note that the largest signals were observed $0.5-1.0 \mathrm{~mm}$ below the transplant. The histochemical correlates in Figure $6 C(1-5)$ show that the releases observed adjacent to the transplant were derived from monoamine-containing nerve terminals from the graft, rather than from residual terminals remaining in the denervated tissue. Thus, areas adjacent to the grafts demonstrated release characteristics that were somewhat similar to control responses. In addition, the reverse current ratios of the signals recorded from the transplant reinnervated sides consistently showed values between 0.2 and 0.5 .

\section{Discussion}

The present data demonstrate that human fetal nigral tissue grafted to the DA-denervated striatum of athymic (nude) rats survives and develops many features typical of similar nigral allografts in rats. Using antibodies specifically directed against
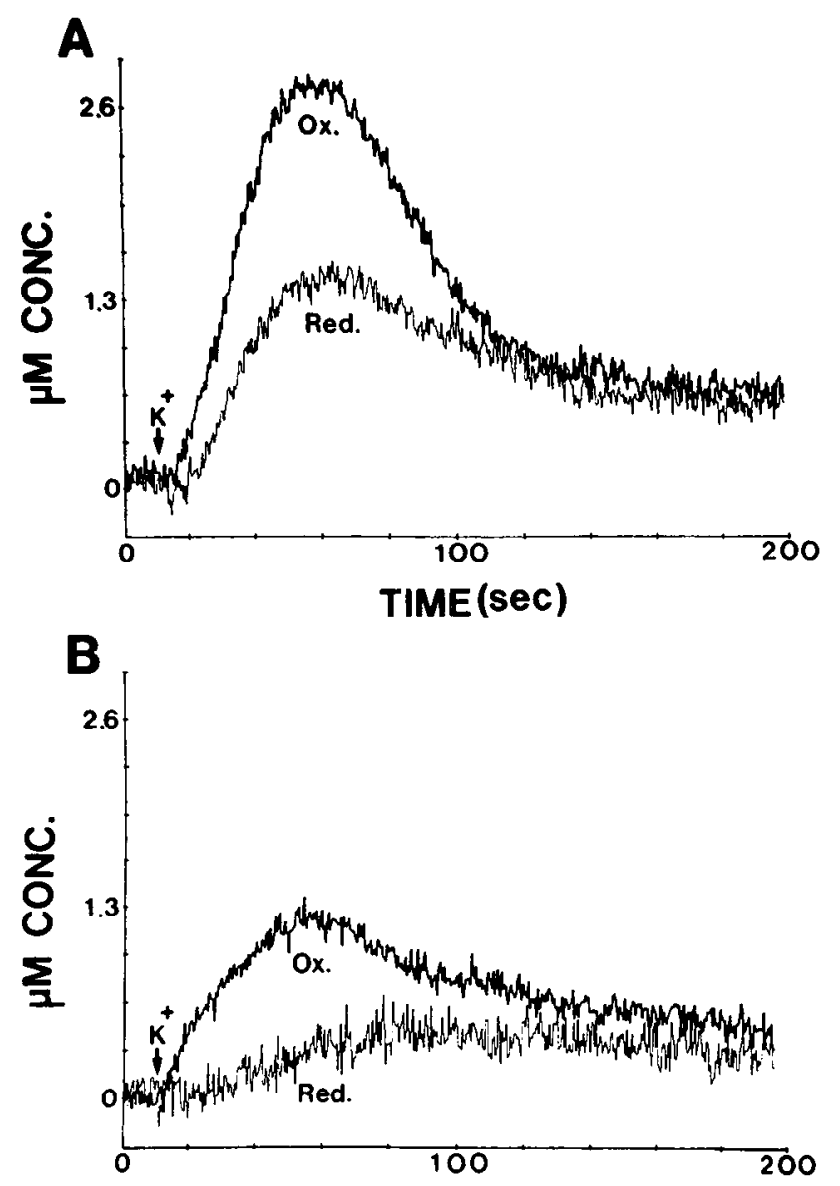

Figure 5. A, High-speed chronoamperometric recording $(5 \mathrm{~Hz})$ of a $\mathrm{K}^{+}$-evoked release recorded from the control caudate nucleus of a transplant-reinnervated rat. $B$, High-speed chronoamperometric recording $(5 \mathrm{~Hz})$ of a potassium-evoked release recorded from a histologically confirmed recording electrode placement within $0.5 \mathrm{~mm}$ of a fetal substantia nigra graft. The $O x$. and Red. markings identify the high-speed oxidation and reduction signals recorded for each potassium ejection.

human Thy-1, a marker of human ncuronal membrancs also during development (cf. Seiger et al., 1986), we could show that the intrastriatal grafts had grown considerably in their rat hosts. The presence of Thy-1-positive processes extending from the human graft into the rat host striatal neuropil suggests that there are no major barriers in this system prohibiting graft-host interactions. The fact that Thy-1-positive fibers in host striatum were also shown by double labeling to be $\mathrm{TH}$-positive is further evidence that the $\mathrm{TH}$-immunoreactive fibers are indeed derived from the grafted human cells.

Laminin immunohistochemistry provides an excellent means of evaluating capillary density and morphology (EriksdotterNilsson et al., 1986). It is interesting to note that the vascularization appears more normal in human fetal tissue grafted into striatum than grafted to the anterior chamber of the eye (cf. Bickford-Wimer et al., 1987; Olson et al., 1987). Thus, in cortex cerebelli transplants placed on the surface of the iris, there were often no laminin-positive blood vessels seen throughout the grafts even after 6 weeks. Two and a half months later, lamininpositive blood vessels were seen throughout the grafts, although the vessel walls were abnormally thick (Bickford-Wimer et al., 1987). Similar types of thick-walled blood vessels also occur in human fetal substantia nigra pieces grafted into cortical cavities 

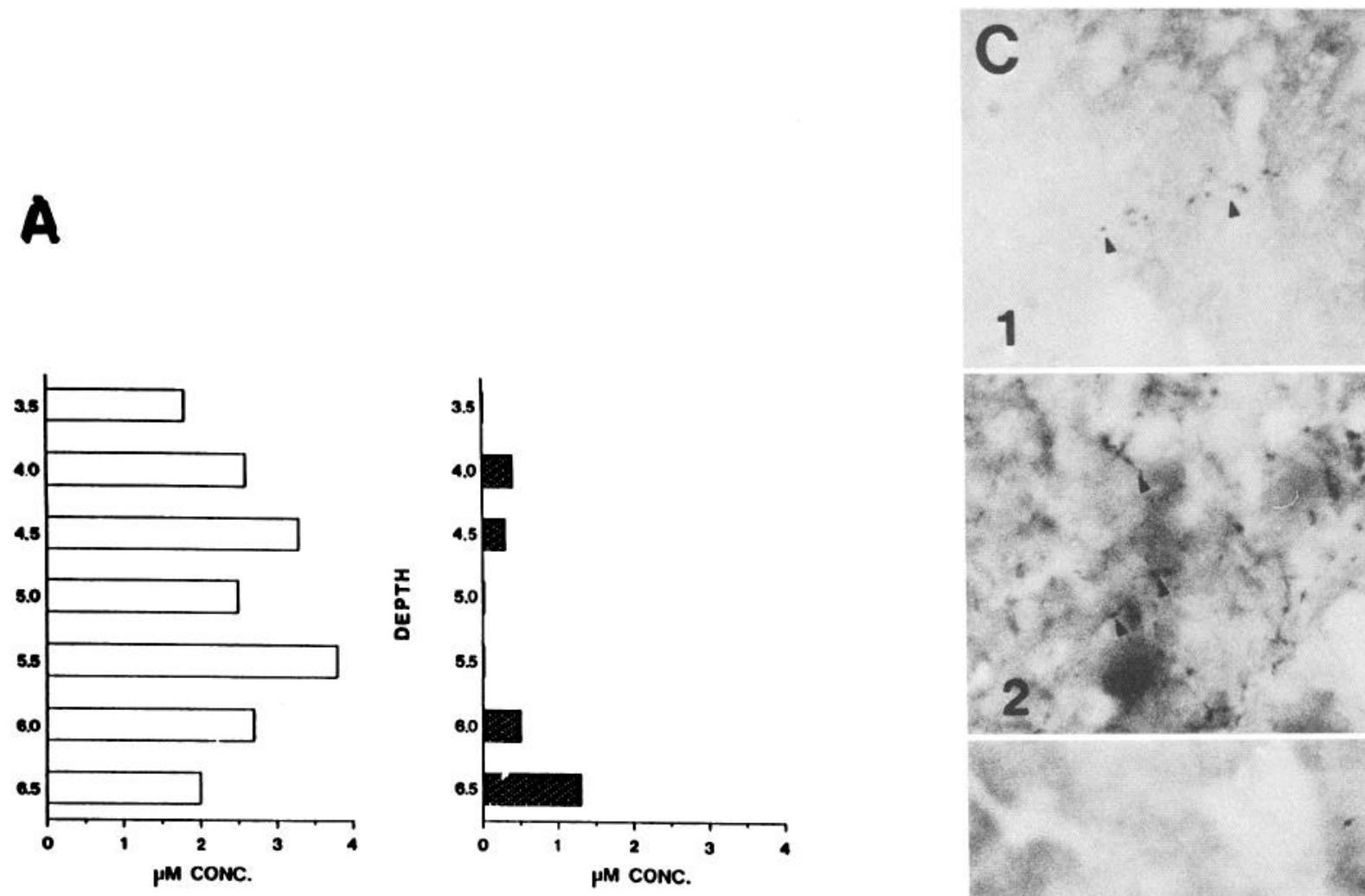

B
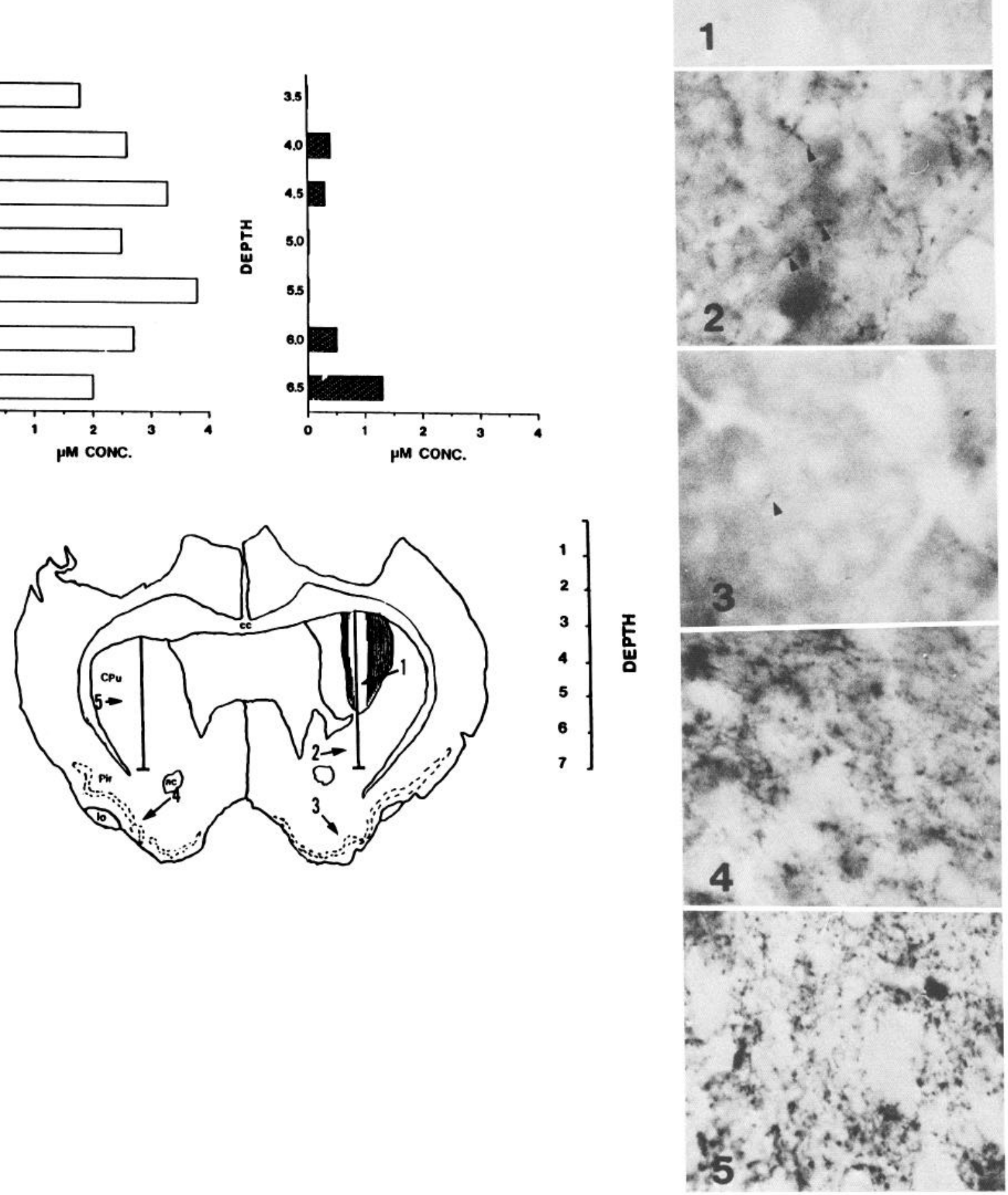

Figure 6. A, Histological reconstruction of the electrochemical recording tracks from the control (left) and transplant-innervated (right) sides of an athymic nude rat. The 2 histograms represent the amplitudes of the electrochemical signals seen at each of the recording depths. Note that the releases observed on the transplanted side are lower than those seen on the control side. $B$, Tracing of a Nissl-stained section through the electrochemical electrode track. Shaded area is grafted human tissue. Numbers on the drawing correspond to the photographic fields shown in $C$. $C$, Micrographs of TH-like immunoreactivity in a plastic-embedded section near the electrochemical recording sites. 1, Sparse TH-immunoreactive nerve fibers (arrowheads) within the graft neuropil; 2, TH-immunoreactive innervation ventral to the graft; 3 , residual TH-immunoreactive innervation in the olfactory tubercle on the 6-OHDA-lesioned side of the brain; 4, TH-immunoreactive innervation on the control side of the brain; 5 , TH-immunoreactive innervation of the control striatum. 
overlying DA-denervated striatum (I. Strömberg, unpublished observations). Thus, it appears as if grafting to a well-vascularized surface such as the iris or a previously prepared cavity will result in a more abnormal development of blood vessels than grafting directly into CNS neuropil. Perhaps a rapid vascularization of the transplant is not needed when the tissuc is placed on a well-vascularized surface, because nutrients can diffuse from the neighboring vessel bed to the graft, as long as the graft has not grown too large. In the grafts implanted to striatum, only normal capillaries are present around the grafts, and this, perhaps, makes it necessary that the graft rapidly develop a capillary network for good nutrition and survival. Alternatively, the abnormal patterns of vascularization seen in oculo and in cavities might reflect vascularization by peripheral-type vessels entering the gratt, while the normal pattern seen in intraparenchymal grafts might reflect ingrowth of CNS-type vessels. The lower capillary density in the grafted tissue than in the host might be explained by the immature state of the grafts at sacrifice since fetal brain tissue generally has a less dense capillary network than adult tissue from the same location.

Two recent studies using human fetal dopamine neuroblast suspensions injected into the DA-denervated striatum of ciclosporin-treated rats reported good survival and fiber production by DA neurons from 9-week-old fetuses, poor survival from 11 -week-old fetuses, and no survival from older fetuses (Brundin et al., 1986, 1988). In the present study, using solid tissue pieces, rather than cell suspensions, it was possible to obtain a relatively good survival of DA neurons from 12-week-old fetuses also. These present data thus support previous results showing that when human fetal nigral tissue pieces from 12week-old fetuses were grafted to a cortical cavity, the survival and fiber outgrowth were good (Strömberg et al., 1986). Perhaps DA ncuroblasts at this stage are more vulncrable during preparations of cell suspensions. It should be noted that the $\mathrm{TH}$ positive cells from a 7 -week-old fetus used in the present study had a more mature appearance at sacrifice than TH-positive cells grafted from a 12-week-old fetus, although the total age of the cells at sacrifice was about the same (i.e., 7 weeks plus 4.5 months vs. 12 weeks plus 3-3.5 months, respectively).

The TH-positive cells were often located in clusters in the periphery of the grafts. In the TH cell-containing areas there was also a large number of TH-positive nerves. Thus, the grafts demonstrated a certain degree of organization with areas somewhat similar to pars compacta of substantia nigra and other areas, usually centrally located in the graft, with many fewer cells and terminals, reminiscent of pars reticulata.

The prior dopaminergic denervation of rat host striatum permitted visualization, by immunohistochemistry at both the light and the electron-microscopical level, of human TH-positive nerve fibers entering the rat host striatal neuropil. Although the outgrowth, at the light-microscopical level, with the present types of dissections and postgrafting times, was not extensive, electron microscopy unequivocally demonstrated TH-positive axon terminals making synaptic contact with TH-negative dendrites. These findings are best explained as synapses formed between human DA nerve terminals and rat striatal neurons. The ultrastructure of the contacts which TH-immunoreactive synapses form with dendrites and dendritic spines is similar to TH-positive synapses found in the rat striatum (Pickel et al., 1976, 1981). In a large majority of cases TH-positive axons were closely apposed to unlabeled dendritic shafts or spines. These contacts were morphologically similar to those described previously in that postsynaptic densities were either missing or very scant and that a widening of the synaptic cleft was present at the point of contact. Given that over $95 \%$ of the nigral THimmunoreactive cell bodies are destroyed on the side of the 6-OHIDA injection, it seems likely that the majority of observed TH-positive terminals originated from the human tissue grafts. As in the normal rat striatum, TH-positive axons rarely formed asymmetrical contacts within the host neuropil. Taken together with the electrochemical data, our ultrastructural observations suggest that the release of DA from graft-derived axons occurred at synapses.

Recently, in vivo electrochemical techniques have been developed to allow studies of monoamine release in the intact brain (for reviews, see Adams and Marsden, 1982; Stamford, 1985). Using in vivo chronoamperometric electrochemical recording techniques, coupled with pressure ejection of drugs from micropipettes, we have begun to investigate both release and uptake mechanisms of DA nerve terminals in the intact rat caudate nucleus (Gerhardt et al., 1985, 1986, 1987; Rose et al., 1985).

Our group and others have shown that Nafion-coated electrochemical electrodes minimize signal interference from monoamine metabolites and ascorbic acid (Gerhardt et al., 1984; Nagy et al., 1985; Mueller, 1986; Brazell et al., 1987; Kelly and Wightman, 1987). However, it was not previously possible to discriminate between DA, 5-HT, and norepinephrine (NE). The combination of the oxidation and reduction current measurements now yields a chemical reversibility ratio that can be used as an index to aid in the further identification of the detected monoamines (Gerhardt et al., 1988a, b). While there is some variability in the values observed for individual recording electrodes, DA consistently yields the highest reduction-to-oxidation current ratio $(0.5-0.7)$, followed by $\mathrm{NE}(0.3-0.5)$, and finally 5 -HT (0.0-0.2). In addition, ascorbic acid, which is irreversibly oxidized at the electrode surface at physiological pH (Stutts and Wightman, 1983), exhibits a ratio of 0.0 . As was seen in Figure $5 A$, a DA-like ratio was observed following a $\mathrm{K}^{+}$-evoked release recorded with a Nafion-coated electrode in the control caudate nucleus. Thus, data obtained with the new electrochemical prolocol support the idea that the signal measured following $\mathrm{K}^{+}$ stimulation in control rat striatum is dopaminergic. However, the reverse current data, as well as histochemical data, support the idea that 5-HT makes a significant contribution to the signals recorded from the transplant-reinnervated caudate nucleus.

Previous studies have provided other pharmacological and anatomical evidence supporting the specificity of Nafion-coated GEC electrodes for monoamines and the release of DA via $\mathrm{K}^{+}$elicited depolarization. $\mathrm{K}^{+}$-evoked signals have been shown to be selective, reversible, and reproducible (Gerhardt et al., 1986, 1987). We have previously reported that pretreatment with DA neurotoxins such as 6-OHDA and MPTP greatly reduce the $\mathrm{K}^{+}$evoked signals recorded in striatal tissue (Gerhardt et al., 1985; Rose et al., 1985). Furthermore, only very small signals are observed from confirmed electrode placements in white matter such as corpus callosum or anterior commissure, where DA nerve terminals are virtually nonexistent (Gerhardt et al., 1986). In addition, local applications of drugs that are known to alter neuronal high-affinity uptake processes, such as nomifensine, phencyclidine, and cocaine, potentiate the magnitudes of the potassium-evoked signals recorded from the caudate nucleus (Gerhardt et al., 1986, 1987, 1988b). Moreover, in a recent study we have used intracranial microdialysis methods to demonstrate 
that excess potassium causes an increase in the extracellular levels of DA, and this effect is also potentiated by the highaffinity catecholamine uptake inhibitor, nomifensine ( $\mathrm{Ng}$ Cheong Ion et al., 1988).

Human mesencephalic tissue grafted to ciclosporin-treated rats rclcascs dopaminc and this release is increased by amphetamine and by nomifensine (Brundin et al., 1988). Similarly, our in vivo chronoamperometric studies demonstrate release of DA in human nigral grafts placed in athymic rats. The in vivo voltammetry permits continuous monitoring of ongoing local release following micropressure ejection of potassium ions while varying the recording sites and demonstrated that the release magnitude is directly correlated to the degree of DA reinnervation.

Clearly, the dissections used in the present study cannot single out the DA neuroblasts only. Several other types of neurons as well as glial cells will, by necessity, be included in the transplants. The low reduction to oxidation current ratios of potassiumevoked signals recorded electrochemically from the transplants suggested that 5-HT was released from graft-derived terminals. This was in contrast to the DA-like ratios observed on the control sides of these animals. The conclusion was supportcd by our immunocytochemical observations, which demonstrated the presence of 5-HT-immunoreactive cell bodies within the grafts, and 5-HT-positive fibers in host neuropil. 5-HT-immunoreactive axons and dendrites were involved in synapses within the host neuropil, suggesting that grafted serotonergic neurons had also become integrated with the host brain. These transplanted serotonergic neurons probably originated from the dorsal raphe.

Taken together, the present results demonstrate the feasibility of using the athymic nude rat as a host for human fetal brain tissue grafts. We have previously used athymic nude rats, grafting human brain tissue to the anterior chamber of the eye (Bickford-Wimer et al., 1987) as an alternative to grafting human fetal tissues to ciclosporin-treated rats (Strömberg et al., 1986; Olson et al., 1987). The advantages of using athymic rats are both practical, in the sense that daily injections of ciclosporin and/or other immunosuppressant drugs can be avoided, and theoretical, in that one does not have to take into account any potentially detrimental effects of the immunosuppressant drugs used. A practical disadvantage with the athymic rats is, however, that they are sensitive to infections and have to be kept under strictly maintained barrier conditions. This is particularly important when studying human fetal brain tissue grafts, since the development of the human brain tissue occurs at a "human" rather than at a rat timetable, making it necessary to maintain the athymic animals carrying such grafts for long periods of time. Under appropriate conditions, however, this model should generate new information about factors controlling human brain development in general and about the feasibility of using human fetal DA neuroblasts as donor material in therapeutic approaches to Parkinson's disease in particular.

\section{References}

Adams, R. N., and C. A. Marsden (1982) Electrochemical detection methods for monoamine measurements in vitro and in vivo. In Handbook of Psychopharmacology, Vol. 15, L. L. Iversen and S. H. Snyder, eds., Chap. 1, Plenum, New York.

Berglund, E., P. Almqvist, H. Lindroos, S. Carlsson, and T. Stigbrand (1987) Antigenic pattern of human brain glycoproteins as described by monoclonal antibodies. J. Neurochem. 48: 809-815.

Bickford-Wimer, P., A.-Ch. Granholm, M. Bygdeman, B. Hoffer, L.
Olson, Å. Sieger, and I. Strömberg (1987) Human fetal cerebellar and cortical tissue transplanted to the anterior eye chamber of athymic rats: Electrophysiological and structural studies. Proc. Natl. Acad. Sci. USA BSci. USA 84: 5957-5961.

Björklund, A., and U. Stenevi (1979) Reconstruction of the dopamine pathway by intracerebral nigral transplants. Brain Res. 177: 555-560.

Björklund, $\Lambda$., U. Stenevi, R. H. Schmidt, S. B. Dunnett, and F. H. Gage (1983) Intracerebral grafting of neuronal cell suspensions. II. Survival and growth of nigral cell suspensions implanted in different brain sites. Acla Physiol. Scand. (Suppl.) 522: 9-18.

Brazell, M. P., R. J. Kasser, K. J. Renner, J. Feng, B. Moghaddam, and R. N. Adams (1987) Electrocoating carbon fiber microelectrodes with Nafion improves selectivity for electroactive neurotransmitters. J. Neurosci. Methods 22: 167-172.

Brundin, P., O. G. Nilsson, R. E. Strecker, O. Lindvall, B. Åstedt, and A. Björklund (1986) Behavioural effects of human fetal dopamine neurons grafted in a rat model of Parkinson's disease. Exp. Brain Res. 65: 235-240.

Brundin, P., R. E. Strecker, H. Widner, D. J. Clarke, O. G. Nilsson, B. Åstedt, O. Lindvall, and A. Björklund (1988) Human fetal dopamine neurons grafted in a rat model of Parkinson's disease: Immunological aspects, spontaneous and drug-induced behaviour, and dopamine release. Exp. Brain Res. 70: 192-208.

Coons, A. (1958) Fluorescent antibody methods. In General Cytochemical Methods, J. Danielli, ed., pp. 399-422, Academic, New York.

Eldred, W. D., C. Lucker, H. J. Karten, and S. Yazulla (1983) Comparison of fixation and penetration enhancement techniques for use in ultrastructural immunocytochemistry. J. Histochem. Cytochem. 31: 285-292.

Eriksdotter-Nilsson, M., H. Björklund, and L. Olson (1986) Laminin immunohistochemistry: A simple method to visualize and quantitate vascular structures in the mammalian brain. J. Neurosci. Methods 17: 275-286.

Festing, M. W., D. May, T. A. Connors, D. Lovell, and S. Sparrow (1978) An athymic nude mutation in the rat. Nature 274: 365-366.

Gerhardt, G. A., A. F. Oke, G. Nagy, B. Moghaddam, and R. N. Adams (1984) Nafion-coated electrodes with high selectivity for CNS electrochemistry. Brain Res. 190: 390-395.

Gerhardt, G., G. Rose, I. Strömberg, G. Conboy, L. Olson, G. Jonsson, and $B$. Hoffer (1985) Dopaminergic neurotoxicity of 1-methyl-4phenyl-1,2,3,6-tetrahydropyridine (MPTP) in the mouse: An in vivo electrochemical study. J. Pharmacol. Exp. Ther. 235: 259-265.

Gerhardt, G. A., G. M. Rose, and B. J. Hoffer (1986) Release of monoamines from striatum of rat and mouse evoked by local application of potassium: Evaluation of a new in vivo electrochemical technique. J. Neurochem. 46: 842-850.

Gerhardt, G. A., K. Pang, and G. M. Rose (1987) In vivo electrochemical demonstration of the presynaptic actions of phencyclidine in rat caudate nucleus. J. Pharmacol. Exp. Ther. 241: 714-721.

Gerhardt, G. A., G. M. Rose, A. P. Gratton, I. Strömberg, L. Olson, and B. J. Hoffer (1988a) In situ analysis of substantia nigra graft function: An electrochemical study. Proceedings of the 6th International Catecholamine Symposium, Liss, New York (in press).

Gerhardt, G. A., A. P. Gratton, and G. M. Rose (1988b) In vivo electrochemical studies of the effects of cocaine on dopamine nerve terminals in rat neostriatum. Physiol. Bohemoslov. 37: 249-257.

Hall, M. E., A. C. Granholm, J. O. Stevens, and B. J. Hoffer (1987) Myocardium and cortex cerebri xenografts transplanted into the anterior chamber of the eye of athymic rats: A morphologic and electrophysiologic profile. Neurosci. Lett. 75: 89-94.

Herrera-Marschitz, M., and U. Ungerstedt (1984) Evidence that apomorphine and pergolide induce rotation in rats by different actions on D1 and D2 receptor sites. Eur. J. Pharmacol. 98: 165-176.

Johnson, D. G., and G. M. de C. Nogueira Araujo (1981) A simple method of reducing the fading of immunofluorescence during Inicroscopy. J. Immunol. Methods 43: 349.

Kelly, R. S., and R. M. Wightman (1987) Detection of dopamine overflow and diffusion with voltammetry in slices of rat brain. Brain Res. 423: 79-87.

Mueller, K. (1986) In vivo voltammetric recording with Nafion-coated carbon paste electrodes: Additional evidence that ascorbic acid release is monitored. Pharmacol. Biochem. Behavior 25: 325-328.

Nagy, G., G. A. Gerhardt, A. F. Oke, M. E. Rice, R. N. Adams, R. B. Moore III, M. N. Szentirmay, and C. R. Martin (1985) Ion exchange 
and transport of neurotransmitters in Nafion films on conventional and microelectrode surfaces. J. Electroanal. Chem. 188: 85-94.

Ng Cheong Ton, J. M., G. A. Gerhardt, M. Friedemann, A. M. Etgen, G. M. Rose, N. S. Sharpless, and E. L. Gardner (1988) The effects of delta-9-tetrahydrocannabinol on potassium-evoked release of dopamine in the rat caudate nucleus: An in vivo electrochemical and in vivo microdialysis study. Brain Res. 451: 59-68.

Olson, L. (1985) On the use of transplants to counteract the symptoms of Parkinson's disease. Background, experimental models and possible clinical applications. In Synaptic Plasticity and Remodeling, C. Cotman, ed., pp. 485-505, Guilford, New York.

Olson, L., I. Strömberg, M. Bygdeman, A.-Ch. Granholm, B. Hoffer, R. Freedman, and $\AA$. Seiger (1987) Human fetal tissues grafted to rodent hosts: Structural and functional observations of brain, adrenal and heart tissues in oculo. Exp. Brain Res. 67: 163-178.

Palmer, M. R., S. M. Wuerthele, and B. J. Hoffer (1980) Physical and physiological characteristics of micropressure ejection of drugs from multibarreled pipettes. Neuropharmacology 19: 931-938.

Perlow, M., W. Freed, B. J. Hoffer, A. Seiger, L. Olson, and R. Wyatt (1979) Brain grafts reduce motor abnormalities produced by CNS damage. Science 204: 643-647.

Pickel, V. M., T. H. Joh, and D. J. Reis (1976) Monoamine synthesizing enzymes in central dopaminergic, noradrenergic and serotonergic neurons. Immunocytochemical localization by light and electron microscopy. J. Histochem. Cytochem. 24: 792-806.

Pickel, V. M., S. C. Beckley, T. H. Joh, and D. J. Reis (1981) Ultrastructural immunocytochemical localization of tyrosine hydroxylase in the neostriatum. Brain Res. 225: 373-385.
Redmond, D. E., J. R. Sladek, R. H. Roth, T. J. Collier, J. D. Elsworth, A. Y. Deutch, and S. Haber (1986) Fetal neuronal grafts in monkeys given methylphenyltetra-hydropyridine. Lancet 1 : 1125-1127.

Rose, G., G. Gerhardt, I. Strömberg, L. Olson, and B. Hofler (1985) Monoamine release from dopamine-depleted rat caudate nucleus reinnervated by substantia nigra transplants: An in vivo electrochemical study. Brain Res. 341: 92-100.

Seiger, §., P. Almqvist, A.-C. Granholm, and L. Olson (1986) On the localization of Thy-1-like immunoreactivity in the rodent and human nervous system. Med. Biol. 64: 109-117.

Stamford, J. A. (1985) In vivo voltammetry: Promise and perspective. Brain Res. Rev 10: 119-135.

Sternberger, L. A. (1979) Immunocytochemistry, 2nd ed., Wiley, New York.

Strömberg, I., M. Bygdeman, M. Goldstein, $\AA$. Seiger, and L. Olson (1986) Human fetal substantia nigra grafted to the dopamine-denervated striatum of immunosuppressed rats: Evidence for functional reinnervation. Neurosci. Lett. 71: 271-276.

Stutts, K. J., and R. M. Wightman (1983) Electrocatalysis of ascorbate oxidation with electrosynthesized, surface-bound mediators. Anal. Chem. 55: 1576-1579.

Ungerstedt, U., and G. W. Arbuthnott (1970) Quantitative recording of rotational behaviour in rats after 6-hydroxydopamine lesions of the nigrostriatal dopamine system. Brain Res. 24: 485-493.

Vos, J. G., J. G. Kreeftenberg, B. C. Kruijt, W. Kruizinga, and P. Steerenberg (1980) The athymic nude rat. II. Immunological characteristics. Clin. Immunol. Immunopathol, 15: 229-237. 